\title{
U.S. Territorial Exclusion in Federal Sentencing Research: Can it be Justified?
}

\author{
Gale Iles*, Vic Bumphus and Karen McGuffee
}

University of Tennessee-Chattanooga, USA

\begin{abstract}
There is a dearth of knowledge on sentencing process and outcomes in Guam, the Northern Mariana Islands, Puerto Rico and the United States Virgin Islands. It is not uncommon for researchers conducting national studies to intentionally exclude data from these American territories. Their actions have been justified on the grounds that territories have "distinctive" characteristics that warrant exclusion. Using federal sentencing data, this study explores whether the sentencing patterns observed in the territories are as "unique" as scholars assume and if so, in what ways and to what extent. Descriptive analysis reveals that attributes of offenders and case processing strategies are similar across the U.S. mainland and its territories. Although multivariate analysis revealed some notable differences (e.g., territories are more punitive than states) the larger finding is that there are more similarities than differences with regards to the processing of cases and outcomes. Implications of the study and directions for future research are discussed.
\end{abstract}

Keywords: American territories, sentencing, U.S. mainland.

\section{INTRODUCTION}

Incorporating multiple theoretical frameworks, methodological approaches, and advanced statistical techniques, sentencing research has become somewhat of a growth industry in the United States. The large volume of studies has been the driving force behind the wide array of recent sentencing reforms. However, while the abundance of studies are instrumental in shedding light on sentencing on the U.S. mainland, the exclusion of territorial data from national datasets ensures that sentencing practices, decisions, and outcomes in the U.S. territories remains cloaked in darkness. The Bureau of Justice Statistics (BJS), for instance, reportedly did not begin collecting year-end data on inmates in territorial correctional facilities until 1995 (BJS 2010). The prior exclusion of the American territories (American Samoa, Guam, Northern Mariana Islands, Puerto Rico, and the U.S. Virgin Islands) from year-end data was unfortunate as it provided an inaccurate picture of inmates in the country as a whole.

Although data is now available, there remains a paucity of sentencing research with regard to the American territories. The scant attention is largely driven by scholarly assumptions that the territories possess "unique" characteristics that render them inappropriate for inclusion in national studies. The exclusion of the territories is problematic for several reasons. First, and at the very least, the territories are part of the United States. Therefore, failure to include

*Address correspondence to this author at the University of TennesseeChattanooga, USA; Tel: 423-425-2241; Fax: 423-425-2228;

E-mail: gale-iles@utc.edu them in national studies portrays a partial and inaccurate picture of courts and the sentencing process in the nation as a whole. Second, any addendums or reforms (e.g., the now advisory nature of the federal sentencing guidelines) to federal sentencing that germinate from empirical studies using U.S. mainland data will also impact the U.S. territories. Their exclusion from national studies thus begs the following questions. Why should the territories be subject to national sentencing policies if they are barred from the evaluation process? How would one know the effectiveness of sentencing reforms in these jurisdictions if they remain methodically excluded from assessments? In fact, without including data from the territories how can one even be assured of compliance to policy recommendations? These queries bring us to a third problem. The lack of attention to the territories deprives the jurisdictions of the accountability measures inherent in the supervision of sentencing behaviors and practices. Without monitoring in the form of empirical research, there is no way to ensure that territorial defendants are receiving the same due process as their counterparts on the U.S. mainland. This is unfortunate, because the same commitment and drive devoted to safeguarding fairness and equality in the sentencing of defendants on the U.S. mainland should also be extended to defendants in the territories.

Lastly, the neglect of territorial data is problematic because there is simply not enough information to justify their exclusion from national studies. More specifically, the unbridled practice of dismissing the territories may be a bit premature. This is presumed to be the case as there are no known studies explicitly designed to explore similarities and differences in case 
processing and sentence outcomes between states and territories. Although lles (2009) has come close by providing a snapshot of federal sentencing in the United States Virgin Islands for fiscal years 1997-2002, she did not explore how similar or different sentencing is as compared to the U.S. mainland. Nevertheless, her work demonstrated a need for future research in the American territories. The purpose of this study is to partially fill that void by exploring whether or not the systematic exclusion of territorial data from national studies is justified. More specifically, our objective is to build on prior federal sentencing research by investigating the similarities and/or differences in federal sentencing practices and outcomes between American territories and states. We seek to determine whether the sentencing patterns and outcomes observed in the American territories are as "unique" as scholars assume, and if so, in what ways and to what extent are they different. We begin with a review of the literature and a discussion of the assumed "uniqueness" of the American territories," commonly used to justify their exclusion and neglect.

\section{REVIEW OF LITERATURE AND THE ASSUME UNIQUENESS OF THE AMERICAN TERRITORIES}

While some researchers specifically note their inclusion of all districts in their studies (Mustard 2001; Steffensmeier \& Demuth 2000; Albonetti, 1997), the common practice among others is to methodically exclude the territories from national datasets (Ulmer, Light \& Kramer 2011; Ulmer, Eisenstein \& Johnson 2010; Farrell, Ward \& Rousseau 2009; Kautt, 2002). Generally speaking, there are two primary rationales typically used for disregarding the American territories. One such rationale was articulated by Kautt (2002: 648) who argued that because states have "additional authorities and privileges than do territories...treating states and territories as comparable may introduce non-random bias." Indeed, a major factor differentiating American territories from the states is the political classification of the islands. Politically speaking, the territories all have in common the fact that they are organizationally classified as an "organized unincorporated United States insular area". The term "insular area" simply refers to a jurisdiction that is neither a state nor a federal district (U.S. Department of Interior Office of Insular Affairs, 2014 - herein "Office of Insular Affairs"). The concept of an "organized territory," means that Congress has enacted an Organic Act for the insular area. The Act serves as each Island's Constitution and typically includes a bill of rights and the stipulations for the area's three branches of government. The Northern Mariana Islands and Puerto Rico have the added distinctions of being designated as Commonwealths. Their status as commonwealths signals a closer relationship with the United States, and hence greater political autonomy than do territories but still less than those granted to states (Office of Insular Affairs, 2014).

The doctrine of "unincorporated" is of much greater significance. The Office of Insular Affairs (2014) defines an unincorporated area as "a United States insular area in which the United States Congress has determined that only selected parts of the United States Constitution apply." Unincorporated areas are essentially under the sovereignty of the United States but are not an "integral part of the United States" (General Accounting Office, 1991: 6). Moreover, unlike residents of incorporated areas (i.e., states), residents of unincorporated areas do not automatically enjoy all the protections of the United States Constitution (Ballentine v. United States 2001; Ballentine v. United States 2007). It is the power and generosity of Congress, not the U.S. Constitution that grants residents of these areas fundamental rights such as the right to a jury trial (Dorr v. United States 1904).

The second rationale used to exclude the American territories is based on the grounds that these jurisdictions possess "distinctive qualities" that makes them unsuited for national studies. In their study on the effects of courtroom diversity on sentencing disparity, for instance, Farrell, Ward \& Rousseau (2009: 125) explained that they eliminated data from the American territories because of the "unique jurisdictional character of these districts". This logic is likely to be embraced by scholars (e.g., Ulmer, 2005; Ulmer, 1997; Dixon, 1995; Eisenstein, Flemming and Nardulli, 1998) who subscribe to the idea that courts operate according to the characteristics of the jurisdictions in which they serve. The underlying premise here is that the contextual features of the local community (e.g., its local legal actors, types of available resources and local practices such as going rates) are going to influence the outcome more so than national directives. Ulmer's social worlds court community perspective, for example, contends that the day-to-day tasks of court community members are shaped not solely by national mandates but also by local "going rates" used by indigenous members of the courtroom workgroup (e.g., judges, prosecutors and defense attorneys). These going rates of punishment said to be molded to reflect the concerns of the contextual features of the local community such as the use and efficiency of case 
processing strategies; alternatives to incarceration and its subsequent effects on the availability of prisons/jails beds, size of the courtroom workgroup, their level of corporation, commitment and stability, and their shared ideologies towards crime and punishment (Ulmer, 1997).

Ulmer's depiction of how courts operate is consistent with the practical/organizational constrains of the focal concerns perspective articulated by Steffensmeier, Ulmer, and Kramer (1998). This perspective deals with the real-world limitations faced by the courts and the consequences for courts, correctional organizations, and other agencies of sentencing decisions. Here, the concern is with the efficiency of the system and may involve attention to organization, individual, or situational factors. This includes, but is not limited to, concerns over the efficiency of the system and availability of correctional or alternative programs (e.g., drug treatment programs, mental health facilities). Although it can be argued that the two perspectives (i.e., court community perspective and the focal concerns perspective) apply equally to courts in the different regions of the U.S. mainland, the perspectives have a bigger impact on territorial courts given their geographical isolation from the U.S. mainland. Both Puerto Rico and the U.S. Virgin Islands are located in the West Indies and therefore may be influenced by Caribbean culture while Guam and the Northern Mariana Islands are situated in the South Pacific. Therefore, like Kautt's (2002) "additional authorities and privileges" argument, the "distinctive qualities" argument appears to give some legitimacy to decisions to bar American territories from national sentencing studies. However, as noted earlier, the decision to omit territorial data may be a bit premature since there are no known studies that have explored whether or not sentencing practices and outcomes in the territories are in fact dissimilar from states. Are the characteristics of offenders in the states different from those in the territories? What are the similarities and/or differences in terms of the processing of cases? Are territorial judges more likely than state judges to incarcerate offenders? And when incarcerated, is the average sentence length for defendants in the states any different than the average length of sentence for defendants in the territories? These are just some of the unanswered questions we intend to address.

\section{DATA AND METHOD}

The current study uses the 2008 Monitoring of Federal Sentencing (MCFS) archival datasets. The comprehensive datasets are compiled by the United States Sentencing Commission and are available via the Inter-Consortium for Political and Social Research. The year 2008 represents the most recent data available at the time of the study. The variable POOFFICE was used to select the cases adjudicated in American territories (Guam, Northern Mariana Islands, Puerto Rico, and the United Sates Virgin Islands). ${ }^{1}$ A dummy coded variable was then created that differentiated territorial cases from state cases ( 0 =territory, $1=$ states $)^{2}$

The sentencing of convicted offenders is a two-step process. The process begins with the decision of whether or not to incarcerate the offender. Once the decision has been made to incarcerate, the next step of the process is to determine the longevity of the sentence. Accordingly, our two dependent variables are the "in/out" decision conceptualized as whether or not the defendant received a prison sentence, and the length of sentence. Sentence length is measured in months and is capped at 470 , which is recognized by U.S. Sentencing Commission as a life sentence.

Our analysis includes the three groups of independent variables ordinarily examined in sentencing research. As presented here, the three groups of variables are somewhat on a grated scale moving from being what is widely considered legally irrelevant to legally relevant factors. Located on one end of the scale are the legally-irrelevant variables (commonly referred to as "extra-legal factors") that represent attributes of the offender. Paramount among this group of variables is the race/ethnicity of the offender (white, black, Hispanic, and other races) and sex $($ male $=0$, female $=1)$. Additional extra-legal factors examined in this research and the extant literature are age (continuous), educational attainment (less than high school, high school graduate, and some college/college graduate), and citizenship status (U.S. citizen $=0$, non-U.S. citizen $=1$ ).

\footnotetext{
${ }^{1}$ The MCFS does not include data for American Samoa. Therefore, our study examines data from only four of the five American territories. It is also important to note that in 1966 the U.S. District Courts in Puerto Rico were placed under Article III of the U.S. Constitution, thus making it a Constitutional Court. Therefore, in the true sense the U.S. District Courts in the U.S. Virgin Islands, Guam and the Northern Mariana Islands are the only three territorial courts. They are designated as such because they were created under Article IV, section 3, cl. 2, of the U.S. Constitution (also known as the Territorial Clause). In any event, since Puerto Rico is not a state and like the Northern Mariana Islands is considered a commonwealth, we for the purpose of this study grouped Puerto Rico's federal courts as a territorial court.

${ }^{2}$ For the purpose of this study the District of Columbia is considered a state and thus is included in all references to stateside discussions.
} 
On the far end of the spectrum are the legallyrelevant variables. The most vital is the presumptive sentence, which takes into consideration the severity of the offense and the defendant's prior record. We measured the presumptive sentence as the adjusted guideline minimum; the minimum sentence a judge can impose without departing from the guidelines. However, if there is a mandatory minimum sentence for drugs and the drug minimum is greater than the adjusted guideline minimum then the drug minimum becomes the presumptive sentence. As was the case with sentence length, the presumptive sentence was logged to control its skewness. To capture potential variation in sentencing departures (see Wu \& Spohn 2010), we categorized guideline departures into no departures, government sponsored downward departures (this includes departures for acceptance of responsibility and substantial assistance departures departures that are awarded to defendants who provide valuable information to the government that leads to the prosecution of others), downward departure, and upward departure. We also examined the nature of the offense by collapsing the 31 primary offenses into four categories (drug trafficking, violent, immigration and other offenses).

Falling somewhere between the extra-legal factors and the legally relevant factors are the case processing variables. This group of variables, which consists of case disposition (plea $=0 ;$ trial $=1$ ) and the defendant's pretrial detention status (bail $=0$; in custody $=1$ ), creates somewhat of a dilemma for researchers for while they are not formally considered legally-relevant and are not technically extra-legal, they nonetheless have been found to influence sentence outcomes. For example, Steffensmeier \& Demuth's (2000) study revealed that for both drugs and non-drug offenses going to trial not only increased the length of sentence, it emerged as one of the strongest predictors of sentence length. With regards to pretrial status, Hagan \& Palloni (1997) found that the odds of conviction and imprisonment were higher for immigrants not because of their legal status, but rather because they were more likely than nonimmigrants to be detained prior to trial.

To identify the similarities and differences in sentencing outcomes between territories and the states an assortment of frequencies, measures of central tendency, and variability was used to scrupulously describe the data. Multivariate analysis was also used to compare and contrast the effects of extra-legal and case processing variables on sentence outcomes. Here logistic regression was employed to assess the effects of our independent variables on the in/out decision. Ordinary least squares regression (OLS) was used to assess the effects of our independent variables on the length of sentence. For our multiple regressions we ran three different models; the first model consists of all territorial cases, the second represents state cases and the third model is combination of territories and states with an added variable that controls for whether the case was adjudicated in the territories versus the states. We believe this side-by-side comparison of the three models makes it easier to compare and contrast sentencing decisions and outcomes in the territories to that of the states.

\section{LIMITATIONS OF THE STUDY}

The current study is the first of its kind, and even so, it is limited in the sense that we are not interested in testing or predicting how the "distinctive" characteristics of the territories influence the processing and outcomes of cases, although we do encourage such a study for future research. Rather, our goal is to identify the similarities and differences that exist in the number, types, and processing of cases between American territories and the U.S. mainland. For that reason our study is also limited in the sense that it does not employ advance statistical techniques, such as hierarchical linear modeling to test the effects of the contextual features of the local court community. Lastly, our study is limited in sense that we only analyzed data from 2008. Therefore, we cannot generalize beyond the year of study.

\section{FINDINGS}

Perhaps the most obvious finding of the study is the finite number of cases adjudicated in the American territories. In 2008 there were a total of 922 federal cases heard in the territories compared to the 75,556 cases adjudicated in the states. The territorial figure represents a mere 1.20 percent of the 76,478 federal cases heard nationwide. Proportionately speaking, for every 10,000 residents 18 and over, the territories hear 9.06 cases versus 10.06 cases in the states.

The descriptive statistics for extra-legal, case processing, and legally relevant factors are displayed in Table 1. Regarding the attributes of the offender, the table reveals very little variation in sentencing between territories and states. Specifically, the typical offender in the states is a 34.9-year old Hispanic male, has less than a high school education, is a U.S. citizen and is convicted of drug trafficking. Likewise, the typical 
Table 1: Descriptive Statistics for Dependent and Independent Variables

\begin{tabular}{|c|c|c|c|c|c|c|c|c|}
\hline & \multicolumn{4}{|c|}{ Territories ( $\mathrm{N}=922)$} & \multicolumn{4}{|c|}{ States $(N=75,556)$} \\
\hline & Freq. & $\%$ & Mean & S.D. & Freq. & $\%$ & Mean & S.D. \\
\hline \multicolumn{9}{|l|}{ Extra-legal Factors } \\
\hline \multicolumn{9}{|l|}{ Race/Ethnicity } \\
\hline Whites & 45 & 5.8 & & & 20,725 & 30.0 & & \\
\hline Blacks & 72 & 9.2 & & & 16,695 & 24.2 & & \\
\hline Hispanics & 570 & 73.2 & & & 28,903 & 41.9 & & \\
\hline Other & 92 & 11.8 & & & 2,714 & 3.9 & & \\
\hline Age & & & 34.02 & 9.92 & & & 34.95 & 10.85 \\
\hline \multicolumn{9}{|l|}{ Gender } \\
\hline Male & 731 & 88.6 & & & 63,524 & 87.2 & & \\
\hline Female & 94 & 11.4 & & & 9,208 & 12.8 & & \\
\hline \multicolumn{9}{|l|}{ Education } \\
\hline Less than HS & 408 & 53.0 & & & 32,949 & 49.3 & & \\
\hline HS grad & 231 & 30.0 & & & 19,792 & 29.6 & & \\
\hline College & 131 & 17.0 & & & 14,047 & 21.0 & & \\
\hline \multicolumn{9}{|l|}{ Citizenship Status } \\
\hline U.S. Citizen & 569 & 68.9 & & & 42,952 & 59.4 & & \\
\hline Non-U.S. Citizen & 257 & 31.1 & & & 29,402 & 40.6 & & \\
\hline \multicolumn{9}{|l|}{ Case Processing } \\
\hline \multicolumn{9}{|l|}{ Pretrial Dent. Status } \\
\hline Bail & 210 & 26.7 & & & 17,671 & 25.1 & & \\
\hline In Custody & 577 & 73.3 & & & 52,817 & 74.9 & & \\
\hline \multicolumn{9}{|l|}{ Mode of Disposition } \\
\hline Plea & 862 & 93.5 & & & 72,755 & 96.4 & & \\
\hline Trial & 60 & 6.5 & & & 2,750 & 3.6 & & \\
\hline \multicolumn{9}{|l|}{ Legally Relevant } \\
\hline Num. Cts. of Convictions & & & 1.40 & 1.41 & & & 1.42 & 2.03 \\
\hline \multicolumn{9}{|l|}{ Criminal History } \\
\hline No & 326 & 41.2 & & & 15,764 & 22.1 & & \\
\hline Yes & 466 & 58.8 & & & 55,724 & 77.9 & & \\
\hline \multicolumn{9}{|l|}{ Departures } \\
\hline No Departures & 681 & 74.4 & & & 43,582 & 59.2 & & \\
\hline Downward & 112 & 12.2 & & & 9,860 & 13.4 & & \\
\hline Government Sponsored & 110 & 12.0 & & & 18,953 & 25.8 & & \\
\hline Upward & 12 & 1.3 & & & 1,183 & 1.6 & & \\
\hline \multicolumn{9}{|l|}{ Primary Offense } \\
\hline Drug Trafficking & 341 & 37.0 & & & 23,965 & 31.7 & & \\
\hline Immigration & 205 & 22.2 & & & 21,224 & 28.1 & & \\
\hline Violent & 117 & 12.7 & & & 9,671 & 12.8 & & \\
\hline Other & 226 & 24.5 & & & 15,098 & 20.0 & & \\
\hline
\end{tabular}


(Table 1). Continued.

\begin{tabular}{|c|c|c|c|c|c|c|c|c|}
\hline & \multicolumn{4}{|c|}{ Territories $(\mathrm{N}=922)$} & \multicolumn{4}{|c|}{ States $(N=75,556)$} \\
\hline & Freq. & $\%$ & Mean & S.D. & Freq. & $\%$ & Mean & S.D. \\
\hline \multicolumn{9}{|l|}{ Drug Types } \\
\hline Cocaine & 152 & 41.4 & & & 6,092 & 23.1 & & \\
\hline Crack & 117 & 31.9 & & & 6,268 & 23.8 & & \\
\hline Heroin & 32 & 8.7 & & & 1,519 & 5.8 & & \\
\hline Marijuana & 30 & 8.2 & & & 6,637 & 25.2 & & \\
\hline Methamphetamine & 21 & 5.7 & & & 4,531 & 17.2 & & \\
\hline Other & 15 & 4.1 & & & 1,274 & 4.8 & & \\
\hline \multicolumn{9}{|l|}{ Sentence Outcome } \\
\hline \multicolumn{9}{|l|}{ Type of Sentence } \\
\hline Non Prison & 157 & 17.0 & & & 8,870 & 11.8 & & \\
\hline Prison & 765 & 83.0 & & & 66,589 & 88.2 & & \\
\hline Length of Sentence & & & 63.1 & 79.37 & & & 56.81 & 91.19 \\
\hline
\end{tabular}

offender in the territories is a 34-year old Hispanic male, has less than a high school education, is an American citizen, and is sentenced for drug trafficking. Further evidence of similarities between territories and states is found in the processing of cases; 73.8 percent of territorial defendants remain in custody prior to trial vs. 74.9 percent of similarly-situated defendants in the states, and 88 percent of defendants in both jurisdictions receive a prison sentence.

A number of differences emerge with respect to legally-relevant factors. First, we find that territorial judges are considerably more likely than state judges to sentence within the guidelines $(74.4 \%$ versus $59.2 \%$ ). While no meaningful differences emerge for downward departures (territories 12.2; states 13.4) and upward departures (territories 1.4\%; states 1.5\%), striking differences are noticeable for governmentsponsored downward departures. Specifically, defendants in the states are more than twice as likely as defendants in the territories to receive a government-sponsored downward departure, 25.8 percent and 12.0 percent, respectively.

With regards to offense type, although drug cases are the most frequent offenses in both jurisdictions, the percentage of drug cases is slightly greater in the territories $(37.0 \%)$ than it is in the states $(31.7 \%)$. Further exploration of the data reveals that over 41 percent of the drug offenses in the territories are cocaine-related compared to less than a quarter (23.1 $\%)$ of state drug cases. The territories also have a larger percentage of crack offenses $(31.9 \%)$ than the states (23.8). However, marijuana makes up a quarter $(25.2 \%)$ of the drug offenses in the states but only eight percent of the drug cases in the territories. The mean counts of conviction are identical across territories and states $(\mathrm{M}=1.4)$ and although defendants in states are more likely than defendants in the territories to receive a prison sentence (88.2 versus 83.0, respectively), once the decision has been made to incarcerate, defendants sentenced in the American territories are recipients of longer prison stays than those sentenced in the states (63.1 months in the territories versus 56.8 months in the states). The longer sentences for territorial defendants occur even though territorial defendants are less likely than stateside defendants to have criminal records (58.8 percent and 77.9 percent, respectively).

Table 2 presents the findings of our logistic regression. In all three models, whites were the only racial/ethnic group to achieve statistical significance. Interestingly, while Model 1 showed that white defendants $(b=1.530)$ in the territories faced a 361.9 percent greater likelihood of receiving a prison sentence than Hispanic defendants, both Models 2 and 3 revealed an opposite story. Model 2, for instance, showed that in the states, the odds of receiving a prison sentence was 17 percent lower for whites $(b=1.186)$ when compared to Hispanics. For Model 3, the probability was even lower in that whites $(b=-.148)$ face a 13.7 percent lesser chance of receiving a prison sentence than their Hispanic counterparts.

One of the variables to show significance in both jurisdictions is non-U.S. citizens. While Model 1 
Table 2: Results of Logistic Regression Analysis Predicting the Likelihood of Imprisonment for Territories, States and for Territories and States Combined

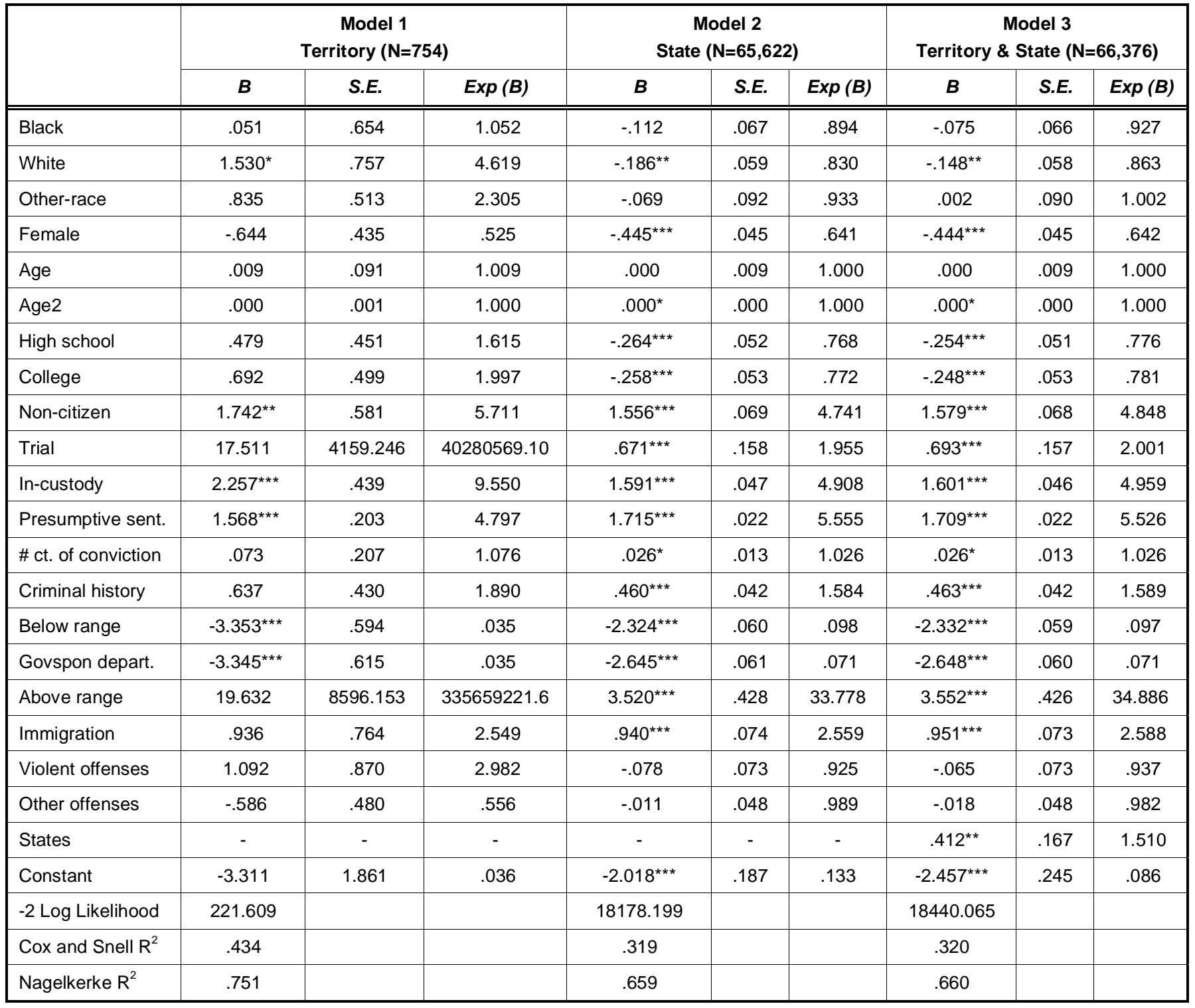

${ }^{*} p<.05 .{ }^{* *} p \leq .01 .{ }^{* \star *} p \leq .001$

showed that non-U.S. citizens in the territories were subject to an average sentence length that is 470 percent longer than U.S. citizens, non-U.S. citizens in the states were awarded sentences that were only 373 percent longer than Americans. Consistent with previous sentencing literature, defendants who were denied bail received sentences that were longer than those given to defendants who were not in custody. Influence on the effects of bail, however, were stronger in the territories $(b=2.257$; an 855.4 percent longer sentence) compared to the states ( $b=1.591$; a 390.8 percent longer sentence). Lastly, the table showed legally-relevant factors as strong predictors of sentence outcomes. In both jurisdictions, for example, the awarding of downward departures and government- sponsored departures resulted in statistically significant lower sentences $(b=-3.353$ and $b=-3.345$ in the territories versus $b=-2.324$ and $b=-2.645$ in the states) than the sentences given to defendants sentenced within the guideline range.

Table 3 presents the findings of our OLS regression. The $R^{2}$ indicates that over 70 percent of the variation in sentencing could be explained by the variables included in each of the models. Similar to our logistic findings, race/ethnicity was found to be statistically significant in all three models. In the territories, black $(b=-.251)$ and other-race $(b=-.184)$ defendants enjoyed sentences that were 22.1 percent and 16.8 percent shorter than those of Hispanics. 
Table 3: Results from OLS Regression Analysis Estimating the Effects of Key Variables on the Length of Sentence in the Territories, States and Territories and States Combined

\begin{tabular}{|c|c|c|c|c|c|c|c|c|c|}
\hline & & $\begin{array}{l}\text { del } 1 \\
y(N=6\end{array}$ & & & $\begin{array}{l}\text { del } 2 \\
\mathrm{~V}=58,\end{array}$ & & Territor & $\begin{array}{l}\text { del } 3 \\
\text { ate }(\mathrm{N}\end{array}$ & 198) \\
\hline & $\boldsymbol{b}$ & S.E. & $\beta$ & $b$ & S.E. & $\beta$ & $\boldsymbol{b}$ & S.E. & $\beta$ \\
\hline White & .003 & .100 & .001 & $.031^{* * *}$ & .009 & .010 & $.031^{* * *}$ & .009 & .010 \\
\hline Other-race & $-.184^{*}$ & .091 & -.041 & -.004 & .016 & -.001 & -.003 & .016 & .000 \\
\hline Age & .012 & .016 & .089 & $.009^{* * *}$ & .002 & .071 & $.009^{* * *}$ & .002 & .072 \\
\hline Age2 & .000 & .000 & -.088 & $.000^{\star * *}$ & .000 & -.070 & $.000^{\star * *}$ & .000 & -.071 \\
\hline High school & -.087 & .056 & -.031 & .009 & .007 & .003 & .008 & .007 & .003 \\
\hline College & -.063 & .073 & -.017 & $-.028^{* * *}$ & .009 & -.008 & $-.028^{* * *}$ & .009 & -.008 \\
\hline Presumptive sent. & $.744^{\star \star *}$ & .025 & .814 & $.880^{* * *}$ & .003 & .845 & $.878^{\star * *}$ & .003 & .845 \\
\hline \# ct. of conviction & .006 & .015 & .007 & $.009^{* * *}$ & .001 & .016 & $.009^{* * *}$ & .001 & .015 \\
\hline Criminal history & $.120^{*}$ & .058 & .044 & $.154^{* * *}$ & .008 & .046 & $.153^{* * *}$ & .008 & .046 \\
\hline Below range & $-.658^{\star * *}$ & .080 & -.162 & $-.585^{\star \star \star}$ & .009 & -.150 & $-.586^{\star \star *}$ & .009 & -.150 \\
\hline Govspon depart. & $-.638^{* * *}$ & .077 & -.168 & $-.704^{* * *}$ & .007 & -.236 & $-.703^{* * *}$ & .007 & -.236 \\
\hline Above range & $.598^{\star \star *}$ & .179 & .063 & $.702^{* * *}$ & .021 & .072 & $.700^{\star * *}$ & .021 & .072 \\
\hline Immigration & -.034 & .100 & -.010 & $.134^{* * *}$ & .010 & .044 & $.133^{\star * *}$ & .010 & .044 \\
\hline Violent offenses & $.140^{*}$ & .070 & .040 & $.040^{* * *}$ & .009 & .011 & $.042^{* * *}$ & .009 & .011 \\
\hline
\end{tabular}

${ }^{*} p<.05 .{ }^{* *} p \leq .01 .{ }^{* *} p \leq .001$.

Contrary to the territories, in the states both blacks $(b=.056)$ and whites $(b=.031)$ tended to receive sentences that were 5.7 percent and 3.1 percent longer than those of Hispanics. An almost identical pattern was uncovered in Model 3 - both blacks $(b=.055)$ and whites $(b=.031)$ were the subjects of harsher penalties when compared to Hispanics (5.6 percent and 3.1 percent longer). Also of importance is the observation that the magnitude of the effects of being black was considerably greater in the territories than in the states. Gender was also found to have a statistically-significant effect on the length of sentence in both jurisdictions. However, the extent of the effect was greater in the territories where females were given a 26.8 percent shorter sentence than males. In the states, females received sentences that were only 15.8 percent shorter than their male counterparts. Also note worthy was the strong influence of case disposition in the territories versus the states. Model 1 disclosed that territorial defendants who went to trial received sentences that were 59.2 percent longer than defendants whose cases were disposed of via plea negotiation. Model 2 showed that similarly-situated defendants in the states who went to trial received sentences that were only 18.8 percent longer than those who plead guilty. Pretrial detention status was also found to be a statisticallysignificant predictor of sentencing outcomes in both territories and states. However, unlike the effects of offender characteristics and going to trial, stronger effects of pretrial detention status were found in the states as opposed to the territories. In the territories, defendants who were denied bail received sentences that were 36.7 percent longer than those awarded bail. For the states, those who remained in custody received 
sentences that were 44.4 percent longer than defendants who were released.

All three models again showed that the legallyrelevant factors have the strongest influence on the sentence length, particularly the presumptive sentence and the variables that represent departure statuses. While territorial defendants who were sentenced above the range received sentences that were 81 percent longer than those sentenced within the guidelines, similarly-situated defendants in the states received sentences that were 101.7 percent longer than those sentenced within the guidelines. The difference in sentence length between those who received a below the range departure versus those sentenced within the guidelines was relatively small; 48.2 percent shorter in the territories compared to 44.2 percent in the states. For recipients of government-sponsored downward departures there was only a three percentage-point difference between territories and states; defendants in the territories who received government-sponsored downward departures were awarded sentences that were 47.1 percent shorter than those sentenced within the guidelines compared to 50.5 percent for state defendants.

In both jurisdictions those with criminal histories were subject to sentences that were longer than those who had no criminal histories. The magnitude of the effects of prior record differed slightly between jurisdictions (defendants with criminal histories in the territories received sentences that were 12.7 percent longer than those without prior records versus 16.6 percent longer sentences for similarly-situated state defendants). With regards to offense type, defendants convicted of violent offenses received longer sentences than those convicted of drug trafficking. However, the effects of violent offense convictions differed substantially between the two jurisdictions. In the territories, defendants convicted of violent offenses received sentences that were 15 percent longer than those awarded to drug offenders, whereas violent offenders in the states received penalties that were only 4 months longer. Lastly, recall that our descriptive analysis in Table $\mathbf{1}$ revealed that defendants adjudicated in the American territories received a mean sentence of 63 months compared to 56 months in the states. Consistent with that finding, Model 3 in Table 3 showed that after holding all things constant, territories are indeed more punitive than their counterparts in the states. The model showed that judges in the states awarded sentences that were 5.3 percent shorter than their territorial peers.

\section{DISCUSSION}

The primary purpose of our study was to compare sentencing decisions and outcomes in the territories, an unexplored venue, to outcomes in the states. The study was an attempt to address the common practice of neglecting the American territories based on an untested assumption that territorial data are "distinctly different" than states. Our effort exposed four observations worthy of discussion. First, we found that with regards to the characteristics of the offenders, there were no real differences between states and territories. In both jurisdictions, the typical offender was depicted as Hispanic, male, had less than a high school education, was a U.S. citizen and was convicted of a drug-related offense. On the surface, the similarities of offender characteristics provided some justification for the inclusion of the territories in national studies. However, we concede that consideration of the racial/ethnic composition of the jurisdictions highlights a major limitation of sentencing data from the American territories.

According to U.S. Census data (2000a), almost half $(44.6 \%)$ of the population of Guam is racially defined as "Native Hawaiian and Other Pacific Islander." Asians (32.5\%) make up the second largest ethnic group (whites-6.8\%; African Americans-1\%). A similar picture emerges for the Northern Mariana Islands where over half $(55.8 \%)$ of the population is classified as Asians and 31.8 percent is classified as Hawaiian and Other Pacific Islanders (U.S. Bureau of Census 2000b). Again, whites (1.8\%) and African Americans (0.1\%) constitute a small share of the islands inhabitants. Turning to the Caribbean, an overwhelming 76.2 percent of Virgin Islanders are classified as African Americans with whites making up 13.1 percent of the population and Asians only 1.1 percent (U.S. Bureau of Census 2000c). Although $75.8 \%$ of the residents of Puerto Rico are classified as white, they are ethnically identified as Hispanics (African Americans -7.3\%; Asians $-0.3 \%$, and Native Hawaiian and Other Pacific Islander-0.2\%)(U.S. Bureau of Census 2000d).

Given the above statistics it comes as no surprise that 100 percent of the defendants sentenced in the Northern Mariana Islands and 91.8 percent of defendants in Guam were classified as "other races." As depicted in Table 1, almost three quarters (73.2 percent) of defendants adjudicated in the territories were classified as Hispanic. Collectively, the racial/ethnic composition of the American territories and the subsequent racial/ethnic characteristics of its 
defendants pose a challenge for researchers, for while whites constitute the numerical "majority" in the states, they represent the "minority" in each of the American territories. In fact, researchers interested only in the dichotomous "white versus black" racial/ethnic category or the traditional tri-categories of "black, white and Hispanic" are justified in excluding data from Guam and the Northern Mariana Islands.

The second finding worthy for further discussion is our observation that just as race/ethnicity has been found to influence sentencing on the U.S. mainland, it also has an effect on sentencing in the American territories. In her work on sentencing in the U.S. Virgin Islands, lles (2009) argued that the racial/ethnic composition of the American territories might signal that harsher punishment based heavily on racial/ethnic stereotypes may not manifest itself in the territories in the same way as it would in the states. She pointed out that it is possible for factors other than race/ethnicity (i.e., class, nationality) to emerge as stronger predictors of sentencing decisions and outcomes in the American territories than in the states. However, in both our logistic and OLS regressions, the race/ethnicity of the defendant unexpectedly emerged as a stronger predictor of sentence outcomes in territories as oppose to the states. Precisely why race/ethnicity is producing stronger association with sentencing outcomes in the territories compared to states is unclear. What is clear is that the findings suggest that the spotlight that shines on the issues and debates of unwarranted racial/ethnic disparity on the U.S. mainland should also be of focus in the American territories. More specifically, our finding advocates the need for including the territories in national studies that examines unwarranted racial/ethnic sentencing disparities.

Our third discussion point centers on our statistically significant case processing and legally relevant variables. In comparing territories with states, all of the models showed consistency in terms of the negative or positive relationships with the dependent and independent variables. What does differ was the extent of the association. For instance, our OLS regression showed that in both territories and states, defendants who opted for trials received harsher sentences than defendants who pled guilty. However, the coefficients in the territories were considerably higher than the coefficients in the states. This indicates that the effect of a "trial tax" (harsher punishment levied on defendants who chose to exercise their right to a trial) is stronger in the territories than in the states. That discovery is tied to our fourth discussion point, which addresses the finding that territorial defendants receive longer sentences than stateside defendants. The observation was apparent in descriptive statistics and confirmed by regression analysis. The finding is not entirely surprising but is consistent with the social worlds/court community and the focal concerns perspectives. When combine both theoretical frameworks suggest that decisions are made within the context of the available resources in the local jurisdiction. For example, despite the small number of cases heard in the territories (less than $2 \%$ of the federal cases heard nationwide), factors such as limited personnel (Guam and the Northern Mariana Islands share the same U.S. Attorney), and lack of correctional facilities (Virgin Islands does not have a federal detention center of its own and thus house federal defendants and inmates in Puerto Rico) may help explain the severity of the penalty imposed upon defendants who consume the limited resources available to the territorial criminal justice system. However, the larger picture here is that case processing strategies are similar in both jurisdictions (territorial as well as state defendants are subject to a trial tax penalty).

\section{POLICY IMPLICATIONS AND DIRECTIONS FOR FUTURE RESEARCH}

In summary, while there were some notable differences in sentencing outcomes between territories and states (e.g., territories are more punitive than states and territorial judges are more likely to sentenced within the guidelines), the findings, as a whole, demonstrated that patterns of sentencing decisions and outcomes in the territories were not uniquely different from state decisions and outcomes. The demographics of offenders were the same, the dynamics of the interplay of race/ethnicity were just as intriguing in the territories as they were in the states, and the processing of cases were similar across both jurisdictions. Given these findings we conclude that the practice of automatically excluding the American territories should be revisited. The policy implications are that including the American territories would provide a more complete picture of federal sentencing in the entire United States. The Ulmer's court community perspective proposes that courts are shaped by local contextual factors that make each jurisdiction unique. Why then should we exclude the American territories on the pretext that they are especially distinctive? The present analysis does not support such a contention. 
More importantly, our findings highlight a need for future research in the American territories. Advanced statistical techniques are needed to investigate the potential influence of the contextual features of territorial communities and their courts. For example, given our findings on the effects of case processing strategies, future research that controls for the number of judgeships, court size and caseloads are encouraged. More sophisticated techniques can also be used to explore whether differences in ideological beliefs are attributable to the islands' political status of not being an "integral" part of the United States. Followup studies that interview members of the courtroom workgroup are also needed to determine if there are differing opinions between U.S. attorneys in states and their territorial counterparts as to what constitutes government sponsored-departures. In closing, the findings of our study suggest that despite the abundance of sentencing literature, there is still a lot to be explored. Adding the American territories to research agendas will undoubtedly continue the growth in sentencing research and at the same time contribute to the breadth of sentencing knowledge in the United States.

\section{REFERENCES}

Albonetti, C. 1997. "Sentencing under the federal sentencing guidelines: Effects of defendant characteristics, guilty pleas, and departures on sentence outcomes for drug offenses, 1991-1992."Law \& Society Review, 31(4):789-822. http://dx.doi.org/10.2307/3053987

Bureau of Justice Statistics. 2010. Territories. Retrieved June 20, 2010 from http://bjs.ojp.usdoj.gov/index.cfm?tv=tp\&tid=144

Demuth, S. 2002. "The effect of citizenship status on sentencing outcomes in drug cases." 14 Federal Sentencing Reporter, 14(5):271-275.

http://dx.doi.org/10.1525/fsr.2002.14.5.271

Dixon, J. 1995. "The organizational context of criminal sentencing." American Journal of Sociology, 100:1157-1198. http://dx.doi.org/10.1086/230635

Eisenstein, J., Flemming, R., and Nardulli. 1988. The contours of justice: Communities and their courts. Boston: Little Brown.

Farrell, A., Ward, G., and Rousseau, D. 2009. "Race effects of representation among federal court workers: Does black workforce representation reduce sentencing disparity." The Annals of the American Academy of Political and Social Science; Race, Crime and Justice: Contexts And Complexities, 623:121-133.

http://dx.doi.org/10.1177/0002716208331128

General Accounting Office 1991. "U.S. insular areas: Applicability of relevant provision of the U.S. Constitution." Report to the ranking minority member, committee on Interior and insular affairs, house of representatives. Available at: http://www.gao.gov/assets/220/214357.pdf Retrieved 2/5/14

Hagan, H. and Palloni, A. 1998."Immigration and crime in the United states." Pp. 367-387 in The immigration debate: Studies on the economic, demographics, and fiscal effects of immigration. James P. Smith and Barry Edmonston (eds). Washington: DC. National Academy Press.
Iles, G. 2009. "The effects of race/ethnicity and national origin on length of sentence in the United states Virgin Islands." The Annals of the American Academy of Political and Social Science; Race, Crime and Justice: Contexts And Complexities, 623:64-76. http://dx.doi.org/10.1177/0002716208330705

Johnson, B. 2005."Contextual disparities in guidelines departures: courtroom social contexts, guideline compliance, and extralegal disparities in criminal sentencing." Criminology, 43(3): 761-796. http://dx.doi.org/10.1111/j.0011-1348.2005.00023.x

Johnson, B., Ulmer, J., and Kramer, J. 2008. "The social context of guidelines circumvention: The case of federal district courts." Criminology, 46(3):737-783. http://dx.doi.org/10.1111/j.1745-9125.2008.00125.x

Kautt, P. 2002. "Location, location, location Interdistrict and intercircuit variations in sentencing outcomes for federal drug-trafficking offenses." Justice Quarterly, 19(4):633-671. http://dx.doi.org/10.1080/07418820200095381

Mustard, D. 2001."Racial, ethnic, and gender disparities in sentencing: Evidence from the U.S. federal courts." Journal of Law and Economics, 44:285-314. http://dx.doi.org/10.1086/320276

Steffensmeier, D. and Demuth, S. 2000. "Ethnicity and sentencing outcomes in U.S. federal courts: Who is punished more harshly." America Sociological Review, 65(5):705-729. http://dx.doi.org/10.2307/2657543

Steffensmeier, D., Ulmer, J. and Kramer, J. 1998. "The interaction of race, gender and age in criminal sentencing: The punishment cost of being young, black, and male." Criminology, 36(4):763-797.

Ulmer, J. 2005. "The localized uses of federal sentencing guidelines in four U.S. district courts: Evidence of processual order." Symbolic Interaction, 28(2):255-279. http://dx.doi.org/10.1525/si.2005.28.2.255

Ulmer, J. 1997. Social worlds of sentencing court communities under sentencing Guidelines. Albany: State University of New York Press.

Ulmer, J., Eisenstein, J. and Johnson, B. 2010."Trial penalties in federal sentencing: Extra-guidelines factors and district variation. "Justice Quarterly, 27(4):560-592. http://dx.doi.org/10.1080/07418820902998063

Ulmer, J., Light, M., and Kramer, J. 2011."The 'liberation' of federal judges' discretion in the wake of the booker/fanfan decision: Is there increased disparity and divergence between courts?" Justice Quarterly, 39(1):1-39.

United States Census Bureau.2000a."Population and housing profile: Guam." Retrieved February 5, 2014, from https://www. census.gov/prod/cen2000/island/GUAMprofile.pdf

United States Census Bureau.2000b. "Population and housing profile: The Commonwealth of the Northern Mariana Islands." Retrieved February 5, 2014, from https://www.census.gov/ $\mathrm{prod} / \mathrm{cen} 2000 /$ island/CNMlprofile.pdf

United States Census Bureau.2000c. "Population and housing profile: U.S. Virgin Islands." Retrieved February 5, 2014, from https://www.census.gov/prod/cen2000/island/VIprofile.pdf

U.S. Bureau of the Census. 2000d. "Summary population and housing characteristics: Puerto Rico." Retrieved February 5, 2014, from https://www.census.gov/prod/cen2000/phc-1-53ENG.pdf

United States Department of Interior: Office of Insular Affairs. "Definitions of insular area political organizations." Retrieved February 4, 2014, from http://www.doi.gov/oia/islands/ politicatypes.cfm\#

Wu, J. and Spohn, C. 2010. "Interdistrict disparity in sentencing in three U.S. district courts." Crime and Delinquency, 56(2):290322.

http://dx.doi.org/10.1177/0011128707309997 


\section{Court Cases}

Ballentine v. United States, Civ. No. 1999-130 (2001).
Ballentine v. United States, 486F.3d 806 (2007).

Dorr v. United States, 195 U.S. 138 (1904).

Received on 07-02-2014

Accepted on 14-03-2014

Published on 20-03-2014

DOI: http://dx.doi.org/10.6000/1929-4409.2014.03.10

(C) 2014 lles et al.; Licensee Lifescience Global.

This is an open access article licensed under the terms of the Creative Commons Attribution Non-Commercial License (http://creativecommons.org/licenses/by-nc/3.0/) which permits unrestricted, non-commercial use, distribution and reproduction in any medium, provided the work is properly cited. 